\title{
SUSTAINABLE ENERGY MANAGEMENT IN THE HEALTH SECTOR
}

\author{
Huda Jaffer and Harish Hande
}

\section{Introduction}

Over half of the health sector's carbon footprint comes from its energy use. Hospitals and healthcare facilities function 24 hours a day, 365 days a year, necessitating continuous energy usage patterns. There are many fuel options for the health sector to choose from, ranging from fossil fuel-based grids to diesel generators, but there are consequences to opting for these choices. The health sector today bears all of the operational costs, including the significant cost of energy, offloading the cost into the public health arena, making it expensive to run many critical care devices and contributing a significant amount towards the greenhouse gas emissions that cause climate change. There are huge opportunities for the health sector to lower its carbon footprint, and consequently make healthcare more affordable, by introducing energy efficiency combined with decentralised reliable renewable energy.

The combination of sustainable energy combined with efficiencies of medical technologies and greener built environments can be one of the most critical components to decrease the health sector's climate footprint. Expensive and unsustainable solutions hinder the replication and scale of sustainable delivery models. A primary assumption being made in healthcare facilities is that existing infrastructure cannot be changed, leading to inefficient solutions that cannot be replicated in other contexts. As in the case of the electricity sector, decentralised energies like solar power have disrupted delivery models, making it available in a more modular form, and consequently more affordable. The availability of sustainable energies, especially for healthcare, in a decentralised mode also pushes innovations in healthcare technologies, increases the efficiencies of medical devices, introduces savings and thermal comforts in health centres through active and passive methods and gives rise to newer delivery models if implemented in a holistic manner. This chapter will examine:

1. Energy usage in the health industry, and how lack of reliable energy sources prevents access to healthcare, especially in rural areas. 
2. An ecosystem-driven approach towards implementing sustainable energy for the health sector.

\section{Energy consumption in the health sector}

Access to reliable energy is a critical barrier to providing accessible sustainable healthcare to all. Effective and optimum utilisation of energy will only take place when the appliances and equipment in the medical profession are designed to be energy efficient while remaining uncompromising on the quality of output. The current inefficiencies in equipment offload the cost of energy onto the public health sector. The health sector today bears all of the operational costs, making it expensive to run many critical care devices, especially in energy-deficient areas. This results in the marginalisation of many populations from availing of reliable health services.

Today, more than half of the world's population lacks access to health services (World Bank and WHO, 2017). Most of the unreached populations reside in the poorest countries, their governments left with no choice but to rely on fossil fuels to power the last-mile health facilities.

A typical medical centre runs continuously all day, every day; internal temperatures need to be carefully controlled for patient safety, human comfort and medical procedures, with energy being consumed by systems for cooling, heating, lighting, ventilation and thermal insulation systems, along with standby generators to ensure an uninterrupted supply of electricity. Autoclave, sterilisation facilities, laundry and catering facilities also require huge amounts of energy for steam, hot water and other thermal applications. These large amounts of energy inputs are not available in remote locations, with the consequence that healthcare facilities in rural remote locations do not have either heating or cooling systems nor critical machines like autoclaves and refrigerators, etc.

\section{Energy efficiency and selected sectors}

While designing medical products, a basic assumption made is that there will be no dearth of reliable energy access to power it. There are two problems that arise from such an assumption: the operational costs of centres with access to energy are not trivial, and centres with unreliable electricity must depend on expensive diesel generators for operation. Inefficient appliances also make decentralised energies such as solar energy seem more expensive than they actually are. Availability of medical devices that are designed for low-resource settings can help the health sector not only to mitigate its carbon footprint, but also to reach the underserved communities.

There is a strong case to be made for a nexus between the efficiency of medical appliances, reliable health services and access to sustainable energy. Low power usage equipment encourages health services to opt for solar energy as a primary source of electricity for reasons of economy and 
reliability. There are some areas in the health sector where energy efficiency methodologies can be adopted immediately, leading to considerable financial savings and environmental impact (Alexander \& Manogaran, forthcoming 2022):

- Maximising the use of natural light in healthcare facilities will help reduce stress levels, and energise employees and patients, as sunlight is beneficial to human health. However, artificial lighting should not be compromised on in sensitive areas such as operation theatres, medical dispensaries, etc.

- Optimising energy efficiency within healthcare facilities simply by turning off energy equipment such as lights, exhausts, air-conditioners, etc. when they are not being used. This can be done through automatic sensors, but it is more economical to sensitise the hospital employees about the issue. Climate-resilient options for lighting, cooling, heating can be easily implemented in the short run, as the technology for this already exists.

- Identifying materials and equipment in the market that have lower environmental impacts. For instance, procuring electronic devices that have been rated as five-star or four-star by the Bureau of Energy Efficiency (BEE) will translate to better savings on energy. Compact Fluorescent Lamps (CFL) can be replaced with light-emitting diodes (LED) lights for more energy savings. Energy metering can identify the facility's energy consumption and indicate opportunities for better efficiency. This option can be used for HVAC systems, and internal and external lighting.

- Investing in renewable energy. This is affordable, safe, economically beneficial in the long run, and provides an opportunity for healthcare facilities to reduce dependency on the grid and be self-sufficient during extreme climate events. A renewable energy backup will decrease the greenhouse gas (GHG) emissions from the facility and enable it to be functional during power cuts.

\section{Lighting}

Lighting is a critical requirement of the health sector for various applications, from patient waiting areas to the operation theatre. Unfortunately, in many primary health centres and sub-centres, the design of the building mandates the requirement of lighting throughout the day. Inefficient bulbs, poor placement of lights and a mismatch of intensity required leads to inefficient usage. Lighting requirements should be customised according to the type of space utilisation and hours of usage. Sensors should be installed in areas of sporadic utilisation, such as rest rooms and corridors. Low intensity LED lighting in waiting areas and high intensity LED with shadow-less fixtures are suitable for operation theatres. A simple and appropriate lighting mapping exercise will save enormous financial resources for individual 
centres without any compromise in quality. Replacing tube lights and incandescent lights with LED can save any centre up to $50 \%$ in lighting costs (Lorenzi, 2019).

\section{Fans}

Fans usage is a major energy expense in the health sector. Again, poor building design and rooms with inappropriate ventilation leads to the unnecessary over-usage of fans. Well-designed buildings with the appropriate placement (wall mounted versus ceiling) of high-efficiency fans can reduce electricity requirements. The benchmark for efficient fans across the world is between 30 and 40 watts, but the ones normally used in India are between 60 and 75 watts, $50 \%$ more than world standards (Sarang, 2015). Solar power is a very viable power source for fans and lights.

\section{Heating}

In a health centre, heating is a crucial requirement for the sterilisation of various instruments, hot water during deliveries, for bathing purposes in patient wards, space heating in colder geographical areas, etc. It is critical to work on the efficiencies of the various appliances used for thermal applications. Inefficient boilers in autoclaves could be directly responsible for increased electricity bills. There are solutions to increase the efficiencies. For example, in-patient needs for hot water can be provided by solar water heaters. Solar water heaters can also supply preheated water to boilers, thus reducing the consumption of other fuels. Autoclaves should be customised for increased efficiency, as it depends on the type and length of usage.

\section{Cooling}

Space cooling is a need that has been underestimated, especially in the health centres of the developing world. The increase in daytime temperatures is being felt by every vertical in the health sector. Take the example of maternal delivery areas and post-delivery rest areas: high day-time temperatures take an enormous toll on mothers and newborn babies. Cooling can no longer be considered a luxury service, but a necessity. Unreliable power and high rates of electricity can be a challenge for many health providers to ensure that the premises maintain temperatures comfortable to human bodies. Fortunately, there are options that can address the challenges of high costs and inefficiencies. Direct current solar-powered air conditioners and other cooling technologies that run on renewables do exist and need to be scaled up. The need for cooling will increase in the future, and health services will have enormous opportunities to show that the alternatives are climate-friendly. Another segment that requires the need for lower temperatures is the storage of medicines and vaccines. The absence or unreliability 
of existing power sources leads to enormous loss of medication and critical vaccines. Again, decentralised solar-powered vaccine refrigerators have proven to be efficient and financially viable for numerous institutions across the world.

The following two case studies capture how the decentralisation of energy generation and access is especially useful in remote areas which are often otherwise unreachable in terms of sustainable healthcare. They showcase the improved reach and increase in impact when health services, energy efficiency and decentralised renewable energy are brought together (Figures 14.1 to 14.3) (Boxes 14.1 and 14.2).

Both the cases studies prove that efficient lighting and appliances powered by solar power can drastically increase the reliability of health services and make it accessible even in the most difficult conditions. Success depends on stakeholders in both the energy and health sectors.

While both these particular cases focused on solar power, other forms of renewable energies can also be explored, for example, using biogas systems for heating or wind turbines for electricity. The chapter titled Green and Resilient Health Infrastructure enumerates the case study of Kohinoor Hospital in Mumbai, which generates $90 \%$ of its energy requirements from a windmill installed offsite. In India however, solar energy is currently one of the easiest options to choose when considering supply chains and aftersales services. Solar systems have proven to be effective in remote areas and even with heavy cloud cover.

There should be a compulsory energy-health assessment at every level of health service. These assessments can help in the identification and procurement of energy-efficient medical appliances and equipment, optimal building and load designs (including utilisation patterns) according to the need of the locality. Climate-resilient options for lighting, cooling, heating can be easily implemented in the short run, as the technology for this already exists. One way to increase the efficiency and lower the costs for the health sector is by the bulk purchasing of equipment by State governments. This was pioneered in a project by the Energy Efficiency Services Limited (EESL), financed by the World Bank for the India Energy Efficiency Scale-up Program (World Bank, 2018) while procuring LED lights.

The health sector, led by critical stakeholders, can set up equivalent standards for efficiency, for both energy and health, along the lines of LEED and GRIHA. These standards can be used as a benchmark not just in India but also in countries in Africa and Latin America.

By making solar and Distributed Renewal Energy (DRE) into an essential component of health networks at the designing stage, the health sector can pave the way for similar approaches for housing and rural development, thus making the scaling of solar power in the country more pragmatic and use-centric.

The Prime Minister's Council on Climate Change, Govt. of India, developed the National Action Plan on Climate Change, under which there are 


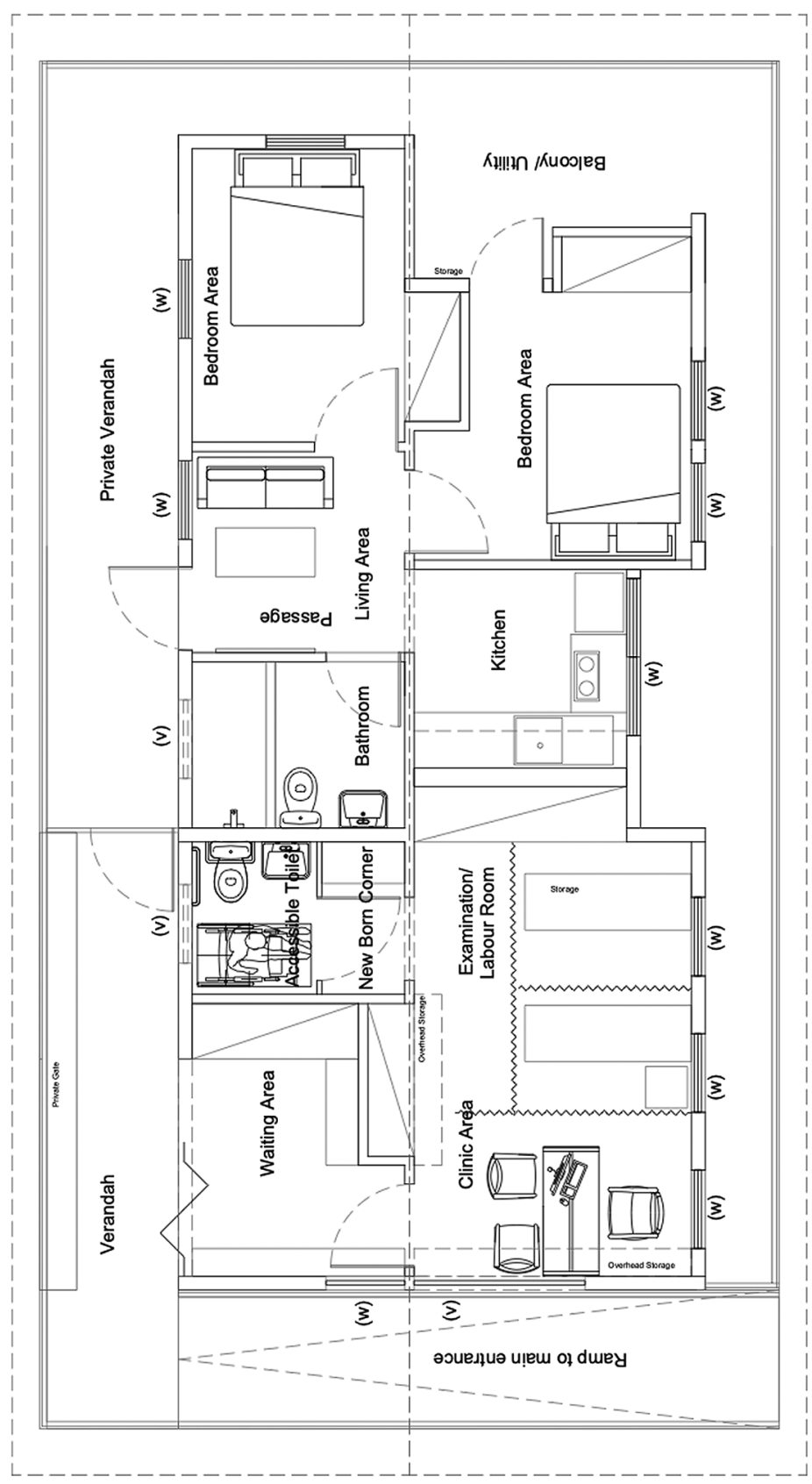

Figure 14.1 The modified KEBA sub-centre layout for maximising thermal comfort through passive build techniques, including efficient health equipment, green building and optimised solar design guidelines.

Source: KEBA Sub-Centre run by Karuna Trust through a PPP Model with the Arunachal Pradesh Health and Family Welfare Department. 


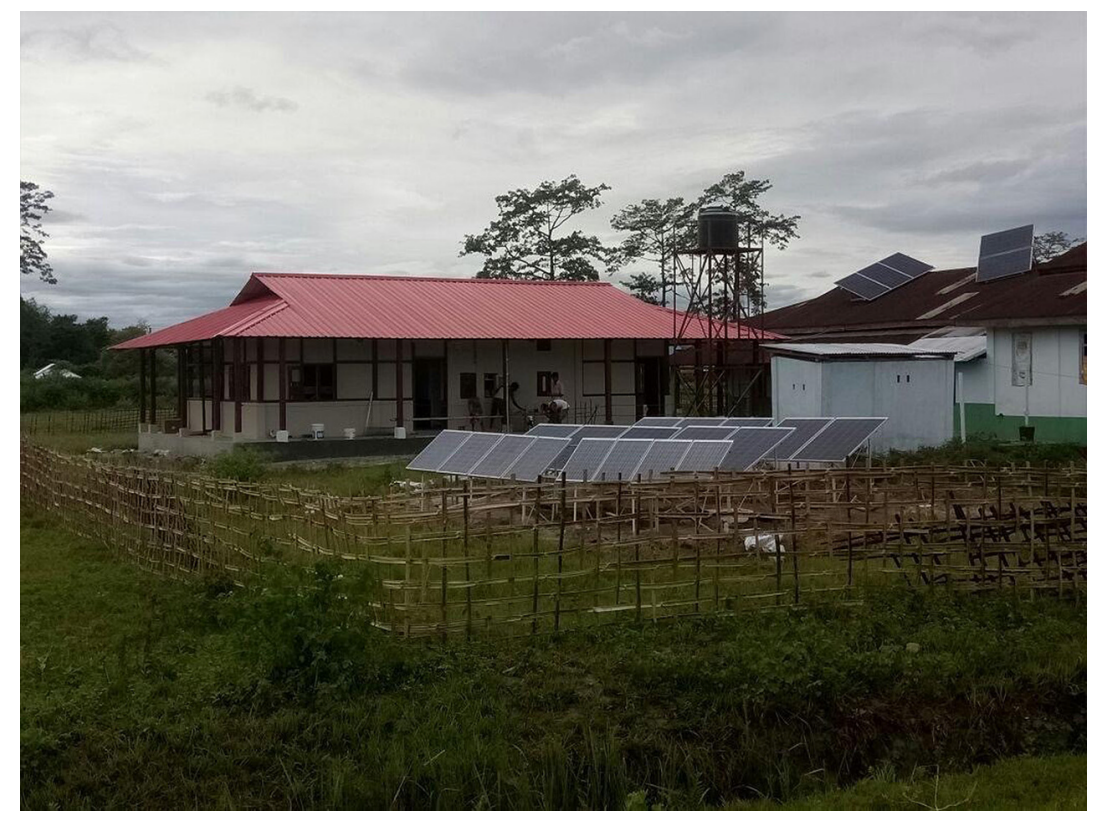

Figure 14.2 The modified KEBA sub-centre.

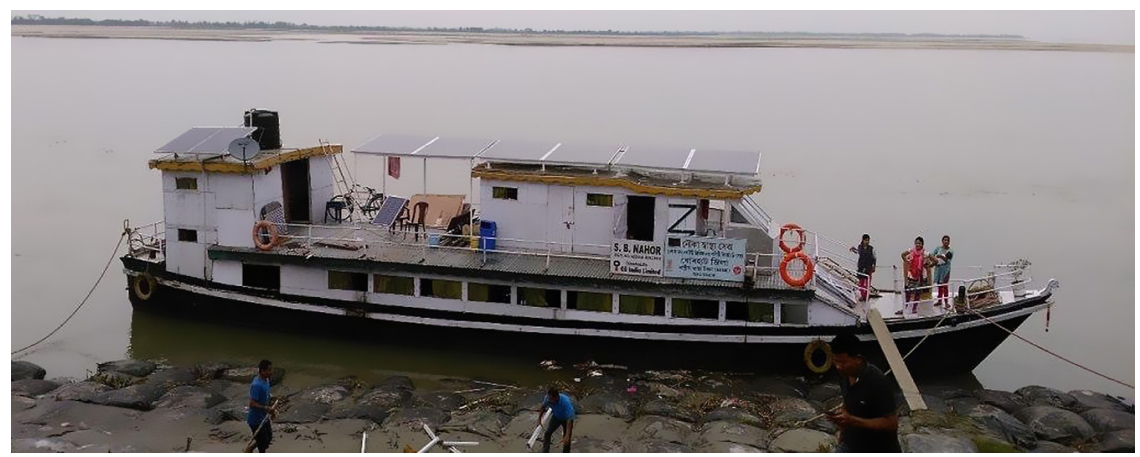

Figure 14.3 The boat clinics within which all health and general appliances are energy-efficient and solar powered.

Source: C-NES Boat Clinics run through the PPP Model with the Assam Health and Family Welfare Department.

twelve missions to address the impact of climate change in our country. Two missions are particularly important in relation to energy: The National Mission for Enhanced Energy Efficiency (NMEEE) and the Jawaharlal Nehru National Solar Mission. 


\section{Box 14.1 Case study}

\section{KEBA health sub-centre in Arunachal Pradesh, India}

Most rural health centres in India have poor natural lighting, lack cross ventilation and are thermally uncomfortable. KEBA, a health sub-centre in Arunachal Pradesh, like many others, was heavily dependent on electricity for basic needs such as lights and fans, with their unreliability and expenses taking a toll on the operations of these centres. The solutions for the problems in KEBA were designed taking into consideration its warm and humid tropical conditions. The centre is located in a remote location with sparse human and financial resources.

To begin with, the centre was physically modified for improved thermal comfort, better ventilation and utilisation of natural light. Locally available construction materials were chosen for modification of the building. The construction technology took into account the low thermal conductivity, the geography and local climatic conditions. The position and size of the windows were redesigned around the path of the sun to reduce solar heat gains. The spatial design of the building was also modified to enhance the ease of use of the space and to improve productivity.

For other lighting needs, including during night-time, energyefficient LED lights providing thermal comfort were designed and installed. The design also took into consideration dry bulb temperature, relative humidity and lux value. Customised lighting was provided in different spaces according to the need and utilisation. The procured medical appliances were energy-efficient. A decentralised solar system was designed to power all the requirements of the KEBA centre. The solar system was designed with extra battery storage backup after accounting for sunshine hours in the region. A solar-powered vaccine storage unit was also designed as per the local climate parameters. In KEBA, there was a reduction in energy consumption for lighting by $80 \%$ and a reduction in energy for fans of over $85 \%$, when compared to sub-centres of similar type and in similar climatic zones. Overall, the KEBA sub-centre consumes $60 \%$ less energy than a comparable sub-centre. The solar powering of the centre therefore led to an overall reduction in electricity bills.

Source: SELCO Foundation 


\section{Box 14.2 Case study Mobile boat clinics on the Brahmaputra River}

The Centre for North East Studies and Policy Research (C-NES) in partnership with the National Health Mission, Government of Assam, has been operating Boat Clinics providing primary health care to the remote island populations in the Brahmaputra and across it since 2005.

The boat clinics provided doorstep health services to people who otherwise had to travel hours to access even basic care. The length of trips of these boat clinics would vary from one day to several days. One of the biggest challenges faced by these mobile clinics was the lack of continuous access to energy to power basic health and communication equipment on the boat. Previously, all these loads were powered by a diesel generator. Diesel is hard to procure on the islands, and the intense noise from the generator makes it difficult to work and stay on the boat.

The Jorhat boat clinic reaches out to approximately 17,000 people and conducts between 18 and 22 camps per month across 34 villages (CNESPR data, 2017). First, all the specific energy needs and hours of utilisation for mobile health unit was mapped. The critical equipment included lights, fans, laboratory instruments, audio-visual devices, vaccine storage, autoclave and dental chair. A solar system was designed keeping in mind the hours of usage, the criticality of the medical appliances, and the space available on the boat for the panels. The solar-powered boat health clinic has led to reliable delivery of health services. It has also led to an increase in staff well-being and a decrease in cost-per-patient for healthcare while avoiding the costs of diesel.

The Bureau of Energy Efficiency (BEE), Govt. of India, operates the NMEEE, which consists of four main initiatives - to improve efficiency in energy-intensive sectors, provide an energy efficiency financing platform, accelerate the shift towards energy-efficient appliances and develop fiscal instruments to promote energy efficiency.

The National Solar Mission aims to promote the consumption of solar energy and establish India as a global leader in solar energy by setting up an enabling environment for penetration of solar technology at the centralised and decentralised level, one example of which was to reduce risks for solar power producers. A renewable energy corridor was launched to develop a dedicated transmission grid for areas with an abundance of sunlight or wind to create solar and wind energy. Solar radiation monitoring stations were also set up across India. The government revised the original target of establishing grid-connected solar power under the NSM from 20 GW by 
2022 to $100 \mathrm{GW}$ by 2022 . This was part of the overall renewable energy target of $175 \mathrm{GW}$, which also includes $60 \mathrm{GW}$ of wind energy, $10 \mathrm{GW}$ of bio-energy, and $5 \mathrm{GW}$ of small hydro-power plants. This five-fold jump in the NSM target has created a huge demand for solar energy projects and equipment. The health sector can also benefit from this initiative by serving the population's health needs while being environmentally sustainable by bringing energy-efficient mechanisms through various stakeholders (both government and private sectors) to all levels of healthcare facilities.

\section{Key takeaways}

- The health sector can lead essential sectors in decreasing their carbon footprint by showcasing the use of energy-efficient equipment and decentralised renewable energy.

- By filling the gaps in providing reliable health services to all, the health sector has a huge opportunity to be climate resilient while being able to democratise its services in a holistic manner.

- The case studies demonstrate how renewable energy sources can greatly increase the reliability of health services and make them accessible even under difficult conditions

- Energy-efficient appliances combined with decentralised solar power can increase the impact of existing health services multifold.

\section{References}

Alexander, D., \& Manogaran, S. (2022, forthcoming). Healthcare and climate change: Implementing green facilities in hospitals. In Dr. Girdhar Gyani \& Dr. Alexander Thomas (Eds.) The handbook of healthcare quality and patient safety ( $3 r d$ ed.). Jaypee.

Centre for North East Studies and Policy Research. (2017). Solar energy to Jorhat Boat Clinic. https://www.c-nes.org/4046/solar-energy-to-jorhat-boat-clinic/

Lorenzi, N. (2019, May 16). Versatility and efficiency drive health care lighting. Health Facilities Management. https://www.hfmmagazine.com/articles/3636versatility-and-efficiency-drive-health-care-lighting

Sarang, B. (2015, March 2). Five ways to keep your power bills low. Economic Times. https://economictimes.indiatimes.com/industry/energy/power/five-waysto-keep-your-power-bills-low/articleshow/46418945.cms?from=mdr

World Bank. (2018). India energy efficiency scale up program. http://documents1. worldbank.org/curated/en/532521527391818294/pdf/India-Energy-EfficiencyScale-up-Program-Project.pdf

World Bank and WHO. (2017). Half the world lacks access to essential health services, 100 million still pushed into extreme poverty because of health expenses. WHO News Release. https://www.who.int/news-room/detail/13-12-2017-worldbank-and-who-half-the-world-lacks-access-to-essential-health-services-100million-still-pushed-into-extreme-poverty-because-of-health-expenses 